1 Secretary of State for Health. The new NHS. London: Stationery Office, 1997. (Cm 3807.)

2 Secretary of State for Wales. NHS Wales: putting patients first. London: Stationery Office, 1998

3 Secretaries of State for Health, Scotland, and Wales. Working for patients London: HMSO, 1989.

4 Majeed A, Malcolm L. Unified budgets for primary care groups. BMI 1999:318:772-6.

5 Smith PC. Setting budgets for general practice in the new NHS. BMJ 1999;318:776-9
6 Proctor SR, Campbell JL. Managing the future in Bradford. BMJ 1999;318:783-5.

Minister for Health and Social Services, Northern Ireland. Fit for the future. Belfast: Department of Health and Social Services, 1998.

8 Secretary of State for Scotland. Designed to care: renewing the National Health Service in Scotland. Edinburgh: Stationery Office, 1997.

9 Dixon J, Holland P, Mays N. Developing primary care: gatekeeping, commissioning and managed care. BMJ 1998;317:125-8.

\title{
Independence days
}

\author{
The practice based structure of general practice is ideally suited to modern \\ primary care
}

$\mathrm{T}$ he creation of primary care trusts has raised the prospect, as perhaps never before, of a substantial shift from the independent contractor status of general practitioners to that of salaried employees. This is not a policy objective, but the forces for change cannot be underestimated and are causing serious concern among most general practitioners. The proposed structure, governing arrangements, and powers of primary care trusts will allow the transition to employed status with greater ease and perhaps persuasion. Equally, there are some general practitioners who see employed status as an answer to the responsibilities of on call work and equity purchase and in any event not core to a general practitioner's primary purpose. $^{1}$ The debate is often ideological and political; we want to examine the concept from evidence based principles of organisational design and behaviour.

Theory about the genesis of organisational structure has long focused on environmental uncertainty and complexity as key concepts that mould structure. ${ }^{2-4}$ Briefly, the more stable an environment, the more rigid the structure, with a list of rigid policies relatively unchanging. The more turbulent an environment, the more is the need to ensure greater flexibility in both the management structure and the way people operate.

The NHS is too often regarded as a homogeneous organism with equivalent environmental determinants throughout it. This is not the case, given the variety of its operational activities ${ }^{4}$ and size, in both expenditure and staff employed. It is such flawed thinking which has often created a seemingly permanent state of structural disequilibrium in the NHS and consequent cyclical demands for "reorganisation."

The operating environment of primary care is one of rapidly changing technology and medical techniques, often creating rather than satisfying demand; pressure on resources; changing data requirements; changing regulations; shifting patient needs and demands because of demographic and social trends; and changing epidemiology and sporadic epidemics. Primary care has to cope with these factors as well as being sensitive, as any service organisation, to demographic changes affecting labour availability. In addition, general practices face competitive threats because of the lowering of barriers for other organisations to deliver aspects of primary care. In short, what might have been considered a complex, though stable, environment is a complex and unstable environment.
Theory (and practice) maintains that an organisation will function best if its social and technological systems (tools, procedures, skills) are designed to optimise the demands of each other and the environment. ${ }^{56}$ For primary care, flat flexible devolved structures with short management decision loops are the best fit-autonomous work groups.

By default or design, this is what independent contractor status with practice employed staff has given us. Yet clearly all is not well: the independence that has permitted innovation and successful adaptation in most places has allowed isolationism and poor practice elsewhere. Clearly it must be a policy goal that the level of service a patient experiences walking into an NHS provider, including primary care, is of an equivalent high standard. The reflex answer of exerting control by subsuming practices into a larger organisation, subject to line management and hierarchical forces, ill fits the requirement of the operating environment of primary care. The idea that true devolution of power could take place in such an arrangement does not square with practical experience of devolution in the NHS.

Attention to motivation is also important in functional development. Poorly motivated individuals are likely to function below their effective level of performance and may influence others and demotivate them. Hackman and Oldham explored several factors related to job design which stimulate intrinsic motivation: meaningfulness, responsibility (autonomy), and knowledge of results. Absence of one or more of these factors was shown to be demotivating. ${ }^{7}$ For many general practitioners, being pressurised, financally or otherwise, into being part of an employing organisation will lead to such absence.

Similarly, continuation of the existing system of independent contractorship without greater accountability for quality is not an option. This may be achieved by clinical governance. However, we profer a third way: practice federation or franchise arrangements. Existing practices would apply for a 5-10 year agreement to deliver primary care within the boundary of the primary care group or trust. The requirements for granting a franchise would cover premises, demonstrable clinical governance, management systems, human resource, and training policies. A practice may supply a plan to make up shortfalls before a given date for franchise renewal. It would remain crucial, for flexibility and response, that practices continued to employ their own staff. In this scenario independence would be
Education and debate p 797 
maintained but within a framework of quality and accountability that does not operate via the heavy hand of quality assurance machinery and costly inspectorates. Instead the process of franchise renewal, overseen by a multidisciplinary governing body (the primary care group or trust), creates a drive for quality improvement within an organisational structure that fits primary care, ensuring appropriate rewards for high quality care.

It is often only when you go abroad that you appreciate things at home, and such it is with our primary care system. It is always a surprise how much it is envied by many in countries who spend more on health. They recognise three features crucial to our success: a defined list of patients, a gatekeeper role to secondary care, and the freedom to innovate. We tamper with any one of those at our peril. Independent status for practices ensures their survival.
John Oldham General practitioner

Manor House Surgery Glossop, Derbyshire SK138PS

Ian Rutter General practitioner

Westcliffe Medical Centre, Shipley, Yorkshire BD18 3EE

The authors are advisers to the NHS Executive primary care division but the views expressed here are entirely their own.

1 Chapman R, Groom H. For and against: should we fight to preserve the independent contractor status of general practitioners? BMJ 1999:318:797-8.

2 Lawrence PR, Larson SW. Organization and environment. Oxford: Oxford University Press, 1967.

3 Buchanan DA, Huczynski AA. Organisational behaviour. New York: Prentice-Hall, 1985.

4 Rowe A, Mason R, Dickel K, Snyder A. Strategic management: a methodological approach. 3rd ed. Reading, MA: Addison Wesley, 1989.

5 Darmore W, Passmore W, Francis C, Haldeman J. Sociotechnical systems. Human Relations 1982;35:1179-1204.

6 Cherry A. Principles of sociotechnical design revisited. Human Relations 1987;40:155-61.

7 Hackman JR, Oldham GR. Wrk redesign. Reading, MA: Addison Wesley, 1980.

\title{
Community development, user involvement, and primary health care
}

\author{
Community development has much to offer to primary care groups
}

$\mathrm{T}$ he new primary care groups (local health groups in Wales) will need to shape services, assess health needs, reduce health inequalities, listen to users' views, and work in partnership with local agencies. This will require a range of skills which few primary health professionals currently have. ${ }^{1}$ Few fundholders undertook any health needs assessment or involved patients in purchasing, ${ }^{2}$ and the government has provided little conceptual, managerial, or financial infrastructure for public involvement. Public meetings are the only mechanism for consultation mentioned in the white paper-yet these are an inadequate means of genuinely engaging communities in the health issues that matter to them, particularly for marginalised groups. One solution is for primary care to work with community development projects, which have been tackling these issues for years.

Community development recognises the social, economic, and environmental causes of ill health and links user involvement and commissioning to improve health and reduce inequalities. Communities can be geographical-such as particular housing estates-or communities of interest, such as user groups. Trained community development workers bring local people together to:

- identify and support existing community networks, thus improving health;

- identify health needs, in particular those of marginalised groups and those suffering inequality;

- work with other relevant agencies, including community groups, to tackle identified needs;

- encourage dialogue with commissioners to develop more accessible and appropriate services. ${ }^{3}$

Many examples of these activities exist. Studies show that community support through social networks is protective of people's health. ${ }^{4}$ High levels of trust and reduced mortality. ${ }^{5}$ Conversely, lack of control, lack of self esteem, and poor social support contribute to increased morbidity. ${ }^{6}$

Needs assessment that is focused on communities can identify solutions as well as problems. Results of such initiatives include a new post of youth health adviser to support youth centred health activities across practices in Lewisham, which has led to improved learning about contraception and sexual health, improved liaison with practices, and changes in practice provision to make services more appropriate for the young people they serve. ${ }^{7}$ In St Peter's Ward, a deprived area of Plymouth, a community development approach has resulted in free pregnancy testing in a local community project, the setting up of a "parentwise" project that draws on resources within the community, changes in health visitors' working, and the provision of more acceptable antenatal classes. ${ }^{8}$ The more involved the community is in needs assessment, the more likely changes are to ensue. ${ }^{9}$ These assessments can provide representative views, particularly if quantitative approaches are used to triangulate these views, and there is little evidence that patients make unreasonable demands.

Community development can also lessen the impact of poverty on health. In Torquay concern about nutrition has led to the setting up of a food cooperative managed by local people that makes available cheap, healthy food. ${ }^{10}$ Community development can reduce social exclusion by ensuring that marginalised groups influence health services. In Bradford such an approach increased the uptake of cervical and breast screening among women from ethnic minorities. ${ }^{11}$ Minority ethnic communities, disabled people, adolescents, and elderly people have all been involved in the commissioning process in Newcastle, where a community development worker, accountable to the commu- 